\title{
PVA-Bloedite $\left[\mathrm{Na}_{2} \mathrm{X}\left(\mathrm{SO}_{4}\right)_{2}(\mathrm{X}=\mathrm{Ni}, \mathrm{Mg})\right]$ Jel Elektrolitlerin Kapasitör Uygulamaları Serkan DEMIREL ${ }^{1 *}$
}

ÖZET: Bloedite tipi olarak adlandırılan $\left[\mathrm{Na}_{2} \mathrm{M}\left(\mathrm{SO}_{4}\right)_{2} \cdot\left(4 \mathrm{H}_{2} \mathrm{O}\right)(\mathrm{M}=\mathrm{Mn}, \mathrm{Zn}, \mathrm{Ni}, \mathrm{Cu}, \mathrm{Fe}, \mathrm{Co})\right]$ malzemeler teknolojik olarak sensör ve enerji depolama sistemlerinde aktif olarak kullanılabilmektedir. $\mathrm{Bu}$ kapsamda $\mathrm{Na}_{2} \mathrm{X}\left(\mathrm{SO}_{4}\right)_{2} \cdot\left(4 \mathrm{H}_{2} \mathrm{O}\right)(\mathrm{X}=\mathrm{Mg}, \mathrm{Ni})$ bloedite malzemelerinin jel forma getirilerek kapasitör elektroliti özellikleri incelenmiştir. Polivinil Alkol (PVA) ile jel forma getirilen Ni ve Mg-bloedite yapılarının cv ölçümleri yapılmış ve $\pm 1 \mathrm{~V}$ bölgesi içinde kalıcı akım düzlüklerine sahip oldukları belirlenmiştir. Kapasitör yapımında paslanmaz çelik folyolar elektrot olarak kullanılmıştır ve yapılan kapasite ölçümlerinde Ni-bleodite $\sim 28 \mathrm{mFg}^{-1}$, Mg-bleodite $\sim 25 \mathrm{mFg}^{-1}$ deşarj kapasitans değerlerine ulaşmıştır. Şarj-deşarj döngüsel kapasitans değeri belirleme çalışmaları kapsamında, 50 döngü sonunda Ni-bloedite yapısının Mg-bloedite yapısına göre iki kattan daha fazla yüksek kapasitans değeri sağladığ belirlenmiştir. Bu farklılık jel elektrolit viskozitesi ile ilişkilendirilmiştir. Yapılan çalışmalar sonucunda PVA-Bloedite yapılı malzemelerin kapasitör enerji depolama sistemlerinde jel elektrolit olarak kullanılmasına uygun olduğu belirlenmiştir.

Anahtar Kelime: Bloedite, Jel Elektrolit, Kapasitör.

\section{Capacitor Applications of PVA-Bloedite $\left[\mathrm{Na} 2 \mathrm{X}\left(\mathrm{SO}_{4}\right)_{2}(\mathrm{X}=\mathrm{Ni}, \mathrm{Mg})\right]$ Gel Electrolytes}

ABSTRACT: The bloedite type $\left[\mathrm{Na}_{2} \mathrm{M}\left(\mathrm{SO}_{4}\right)_{2} \cdot\left(4 \mathrm{H}_{2} \mathrm{O}\right)(\mathrm{M}=\mathrm{Mn}, \mathrm{Zn}, \mathrm{Ni}, \mathrm{Cu}, \mathrm{Fe}, \mathrm{Co})\right]$ materials are actively used in technology as sensors and energy storage materials. In this context, bloedite $\mathrm{Na}_{2} \mathrm{X}\left(\mathrm{SO}_{4}\right)$ 2. $\left(4 \mathrm{H}_{2} \mathrm{O}\right)(\mathrm{X}=\mathrm{Mg}, \mathrm{Ni})$ materials were transformed into a gel form with Polyvinyl Alcohol (PVA), and, their capacitor electrolyte properties were examined. According to cv measurement results, it was determined that $\mathrm{Ni}$ and $\mathrm{Mg}$-bloedite structures had permanent current regions in $\pm 1 \mathrm{~V}$ range. In the experimental capacitor construction, stainless steel foils were used as electrodes. Ni-bleodite reached $28 \mathrm{mF} \mathrm{g}^{-1}$, and, $\mathrm{Mg}$-bleodite $\sim 25 \mathrm{mF} \mathrm{g}^{-1}$ discharge capacitance values. The cycle life studies show that after 50 cycles, Ni-bloedite structure provide more than twice capacitance value compared to $\mathrm{Mg}$ bloedite structure. This difference has been associated with gel electrolyte viscosity. As result of the studies, it has been determined that PVA-Bloedite structure are suitable for use as a gel electrolyte in capacitor energy storage systems.

Keywords: Bloedite, Gel Electrolyte, Capacitor.

\footnotetext{
${ }^{1}$ Serkan DEMİREL (Orcid ID: 0000-0003-1158-4956), Elektrik ve Enerji Bölümü, Teknik Bilimler Meslek Yüksekokulu, Iğdır Üniversitesi, Iğdır, Türkiye.

*Sorumlu Yazar/Corresponding Author: Serkan DEMIREL, serkan.demirel@igdir.edu.tr

Geliş tarihi / Received: 10-04-2020

Kabul tarihi / Accepted: 25-06-2020
} 


\section{GİRiş}

Enerji depolama sistemlerinden biri olan kapasitörler için elektrolit aktif materyalleri büyük önem taşımaktadır. Yüksek kapasitans, yüksek verimlilik, düşük maliyet, kimyasal ve fiziksel kararlılık ve kolay sentezlenebilirlik her zaman ön planda tutulmaktadır (Gonzalez ve ark., 2016). Bu özelliklere uygun olarak kapasitörlerde $\mathrm{KOH}, \mathrm{H}_{2} \mathrm{SO}_{4}, \mathrm{Na}_{2} \mathrm{SO}_{4}, \mathrm{LiOH}$ ve $\mathrm{KCl}$ sulu çözeltileri yaygın olarak kullanılmaktadır (Gonzalez ve ark., 2016). Belirtilen bileşik ve yapılar her ne kadar yüksek performans sağlasa da sahip oldukları toksik yapı, iletkenlik, viskozite, kararlılık ve muhafaza sorunları nedeniyle bazı sıkıntılar ortaya çıkmaktadır (Gonzalez ve ark., 2016; Zhong ve ark., 2015). Bu kapsamda araştırmacılar geçmişten günümüze kadar gelen süreçte bu malzemelere alternatif olabilecek yeni materyaller üzerine çalışmaktadırlar.

Normal şartlarda 3 farklı fiziksel özellikte kullanılabilen elektrolit malzemeleri katı, sıvı ve jel olarak sentezlenmektedirler. Kapasitif performans açısından en yüksek performans sıvı elektrolitler ile sağlanırken, sıvı elektrolitlerin sahip olduğu yüksek iletkenlik kapasitör içinde ayrıca yalıtkan bir membran kullanımını gerektirmektedir (Demirel, 2020; Gonzalez ve ark., 2016). Bunun dışında sıv1 elektrolitlerin toksik yapısı ve muhafaza sorunları nedeniyle güvenlik sorunları bulunmaktadır (Demirel, 2020; Gonzalez ve ark., 2016). Diğer taraftan katı elektrolitler muhafaza ve güvenlik yönünden en yüksek performansa sahip olsalar da kapasitif performansları çok düşüktür. Jel elektrolitler ise kapasitif performans olarak katı ve sıvı elektrolitler arasında yer almakta ve güvenlik ile membran kullanımı açısından sıvı elektrolitlere göre daha avantajlıdır. Özellikle jel elektrolitlerin hemen hemen hepsinde yalıtkan membran kullanımına ihtiyaç duyulmamaktadır (Demirel, 2020; Gonzalez ve ark., 2016).

1940 y1lından beri üzerine çeşitli çalışmalar yapılan Bloedite-tip $\mathrm{Na}_{2} \mathrm{M}\left(\mathrm{SO}_{4}\right)_{2} \cdot\left(4 \mathrm{H}_{2} \mathrm{O}\right)(\mathrm{M}=\mathrm{Mn}$, $\mathrm{Zn}, \mathrm{Ni}, \mathrm{Cu}, \mathrm{Fe}, \mathrm{Co}$ ) yapılı sistemler alkali iyonların hareketi için sağladıkları geniş alanlar nedeniyle teknolojik olarak UV-sensör ve enerji depolama sistemlerinde elektrot aktif maddesi olarak kullanılmaktadır (Rong-rong ve ark., 2011). Özellikle hem Li-iyon hem de Na-iyon bataryalarda elektrot olarak kullanılabilen Bloedite-tip malzemeler yapısal kararlılık ve kristal yapı içerisinde sahip olduğu geniş iyon transfer yolları ile kapasitörlerde denenme fikrini açığa çıkarmıştır (Rong-rong ve ark., 2011; Pal ve ark., 2019; Marinova ve ark., 2018; Ventosa ve ark., 2016; Reynaud ve ark., 2014).

$\mathrm{Bu}$ kapsamda $\mathrm{Na}_{2} \mathrm{X}\left(\mathrm{SO}_{4}\right)_{2} .\left(4 \mathrm{H}_{2} \mathrm{O}\right)(\mathrm{X}=\mathrm{Mg}, \mathrm{Ni})$ sisteminin geniş teknolojik uygulanabilirlik özelliğinden faydalanarak kapasitörlerde jel elektrolit aktif maddesi olarak denenme çalışmaları yapılmıştır. Ni ve Mg-bloedite sistemleri ile literatürde ilk defa denenecek olan PVA-Bloedite jel elektrolit araştırmasında en temel düzeyde en fazla kapasite değerinin elde edilmesi amaçlanmıştır. Yapılan deneysel çalışmalar kapsamında $\mathrm{Ni}$ ve Mg-bloedite malzemeleri basit iki aşamada toz halinde sentezlenmiş ve sonrasında bir polimer türü olan Polivinil Alkol (PVA) kullanılarak jel forma getirilmiştir. Yapısal karakterizasyon ölçümlerinde Ni ve Mg-bloedite yapılarının benzer kristal ve bağ yapılarına sahip oldukları belirlenmiştir. Jel formdaki $\mathrm{Ni}$ ve $\mathrm{Mg}$-bloedite elektrolitler ile paslanmaz çelik folyolar kullanılarak basit kapasitör uygulamaları oluşturmuş ve en basit düzeyde elde edilebilecek maksimum kapasitans değerleri belirlenmiştir. Çalışmalar sonucunda elde edilen miliFarad seviyesindeki kapasitans değerleri ile $\mathrm{Na}_{2} \mathrm{X}\left(\mathrm{SO}_{4}\right)_{2} .\left(4 \mathrm{H}_{2} \mathrm{O}\right)(\mathrm{X}=\mathrm{Mg}, \mathrm{Ni})$ sistemlerinin kapasitörlerde jel elektrolit materyali olarak kullanım uygunluğu belirlenmiştir.

\section{MATERYAL VE YÖNTEM}

Mg-Bloedite ile Ni-Bloedite örneklerin sentezlenmesinde \%97 saflıkta $\mathrm{Na}_{2} \mathrm{SO}_{4}, \mathrm{NiSO}_{4} .6\left(\mathrm{H}_{2} \mathrm{O}\right)$, $\mathrm{MgSO}_{4} .7\left(\mathrm{H}_{2} \mathrm{O}\right)$ ve saf su kullanılmıştır. Sentez prosesinde Ni-bleodite için 1 mol $\mathrm{NiSO}_{4} .6\left(\mathrm{H}_{2} \mathrm{O}\right)$ ve 1 mol Na $\mathrm{SO}_{4}, \mathrm{Mg}$-bleodite için 1 mol $\mathrm{MgSO}_{4} \cdot 7\left(\mathrm{H}_{2} \mathrm{O}\right)$ ve 1 mol Na $2 \mathrm{SO}_{4}$ tozları ile $50 \mathrm{~mL}$ ' lik iki çözelti 
oluşturulmuştur. Çözeltiler daha sonra 12 saat süresince $60^{\circ} \mathrm{C}$ sıcaklıkta manyetik karıştırıcı ile karıştırılmıştır. Bu süreçte $\mathrm{Mg}$ ve Ni-bloedite için oluşan reaksiyonlar (Rong-rong ve ark., 2011);

$$
\begin{gathered}
\mathrm{Na}_{2} \mathrm{SO}_{4}+\mathrm{NiSO}_{4} \cdot 6 \mathrm{H}_{2} \mathrm{O} \rightarrow \mathrm{Na}_{2} \mathrm{Ni}\left(\mathrm{SO}_{4}\right)_{2} \cdot 4 \mathrm{H}_{2} \mathrm{O}+2 \mathrm{H}_{2} \mathrm{O} \\
\mathrm{Na}_{2} \mathrm{SO}_{4}+\mathrm{MgSO}_{4} \cdot 7 \mathrm{H}_{2} \mathrm{O} \rightarrow \mathrm{Na}_{2} \mathrm{Mg}\left(\mathrm{SO}_{4}\right)_{2} \cdot 4 \mathrm{H}_{2} \mathrm{O}+3 \mathrm{H}_{2} \mathrm{O}
\end{gathered}
$$

olarak gerçekleşmektedir. 12 saatlik süreç ardından iki çözelti, 2 gün süresince sabit $40{ }^{\circ} \mathrm{C}$ ' de tutularak saf suyun buharlaşması sağlanmıştır. Buharlaşma sonucunda Ni-bloedite ve Mg-bloedite tozları elde edilmiştir.

Yapısal karakterizasyon işlemlerinde Perkin Elmer marka IR-spektrometre kullanılmıştır. 500$1500 \mathrm{~cm}^{-1}$ aralığında gerçekleştirilen kızılötesi ışınlarla yapılan taramada bloedite yapılarına ait băg titreşimleri belirlenmiştir.

Jel kapasitör elektroliti yapımında $30 \mathrm{~mL}$ saf su içerisinde 0.1 ' er molar Ni-bloedite ve $\mathrm{Mg}$ bloedite tozları ile çözelti oluşturulmuştur. Bu işlemin ardından $30 \mathrm{~mL}$ suyun \%5' i oranında PVA tozu katkılanmıştır. PVA tozunun su içinde çözülmesi ve jel oluşumunun sağlanması için karışım manyetik karıştırıcıda yaklaşık 1 saat süresince karıştırılmıştır. Bu işlemin ardından jel formdaki elektrolitler elde edilmiştir.

Kapasitör yapımında $1 \times 3 \mathrm{~cm}^{2}$ ebatlarında iki adet paslanmaz çelik folyo elektrot olarak kullanılmıştır. Kapasitör hücresine batırılan elektrotların $1 \times 1 \mathrm{~cm}^{2}$ alanı elektrolit ile temas ettirilmesi sağlanarak ölçüm ve hesaplamalar yapılmıştır.

Elektrokimyasal ölçümler için Wheestat marka taşınabilir potansiyostat kullanılmıştır. Döngüsel voltametri (cyclic voltammetry (cv)) ölçümlerinde 3 elektrot yöntemi kullanılmış, grafit çubuklar aktif (working) ve karşıt (counter) elektrot olarak, $\mathrm{Ag} / \mathrm{AgCl}$ elektrot ise referans elektrot olarak kullanılmıştır. CV ölçüm işlemleri 100, 200 ve $400 \mathrm{mV} \mathrm{s}^{-1}$ sabit tarama hızlarında yapılmıştır. Kapasitör ölçümlerinde ise klasik iki elektrot metodu kullanılmış ve 0-1 V aralığında sabit $400 \mathrm{mV} \mathrm{s}^{-1}$ tarama hızı ile 50 döngü cv ölçüm sonucu elde edilmiştir. Bu işlemin ardından kapasitans hesabı cv sonuçlarına bağlı olarak (1) nolu eşitlik ile hesaplanmıştır (Demirel, 2020).

$$
C=\frac{\int I \cdot d v}{2 \cdot m \cdot \Delta V \cdot v}
$$

Denklemde, $I$; akım, $m$; aktif madde ağırlığı, $v$; tarama hızı, $\Delta V$; voltaj aralığı.

\section{BULGULAR VE TARTIŞMA}

Şekil 1 Jel olarak sentezlenen Ni-bloedite ve Mg-bloedite elektrolit materyallerine ait IRspektrum sonuçlarını göstermektedir. Çizelge 1 ise bu sonuçların literatüre göre titreşim modları analizini göstermektedir. IR analizine göre Ni-bloedite ve Mg-bloedite örnekleri benzer yap1 sergilemekte ve bu sonuçlar genel olarak literatür ile uyum sağlamaktadır. Bu kapsamda iki örnek başarılı bir şekilde sentezlenmiştir. Ayrıca IR pik analizleri yapıldığı zaman $\mathrm{SO}_{4}{ }^{2-}$ titreşim modlarının dominant olduğu görülmektedir. $980 \mathrm{~cm}^{-1}$ karakteristik Ni-bloedite $\mathrm{SO}_{4}{ }^{2-}$ modu ve $987 \mathrm{~cm}^{-1}$ karakteristik $\mathrm{Mg}$-bloedite $\mathrm{SO}_{4}{ }^{2-}$ moduna ait olduğu belirlenmiştir. Her iki örnekte de $\mathrm{SO}_{4}{ }^{2-}$ titreşim modlarının bu denli baskın olması $\mathrm{S}$ ve $\mathrm{O}$ atomlarının $\mathrm{Ni}$ ve $\mathrm{Mg}$ metal merkezlerinin etrafında bă yapmasından kaynaklanmaktadır (Yahia, 2019). Na atomları ise bu yapının daha iç kısımlarında bulunmakta ve Mg$\mathrm{S}-\mathrm{O}$ ile Ni-S-O bağlarından oluşan kafes yapılar içinde kalması nedeniyle $\mathrm{SO}_{4}{ }^{2-}$ bağ titreşimlerinin baskınlığı görülmektedir. Ayrıca Çizelge 1' de belirtilen pik değerlerine bağlı olarak 1091, 1096, 1168, $1171 \mathrm{~cm}^{-1}$ asimetrik ve simetrik $\mathrm{SO}_{4}{ }^{2-}$ bağ titreşimlerine ve $599,601,638,639 \mathrm{~cm}^{-1}$ asimetrik S-O bağ titreşimine ait olduğu belirlenmiştir (Marinova ve ark.,2017; Kasatkın ve ark., 2013). Benzer şekilde 812 
ve $813 \mathrm{~cm}^{-1}$ PVA yapısından gelen $\mathrm{C}-\mathrm{O}$ bağ titreşimleri, 1039 ve $1042 \mathrm{~cm}^{-1} \mathrm{C}-\mathrm{H}$ titreşimlerini göstermektedir (Chang ve ark., 2007).

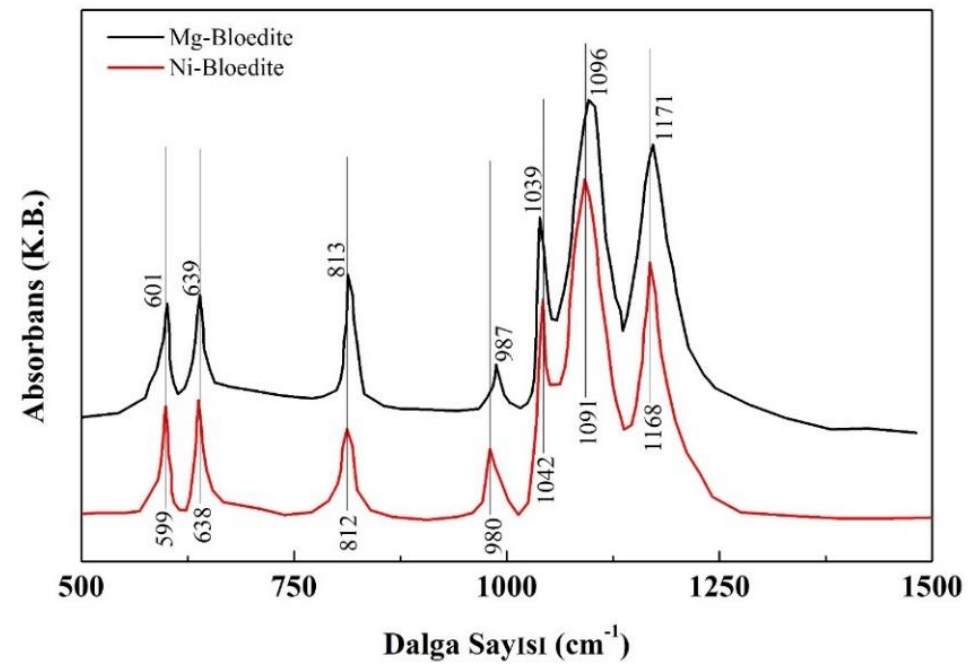

Şekil 1. Jel Ni-bloedite ve Mg-bloedite örneklerinin IR-spektrumu.

Çizelge 1. Ni-bloedite ve Mg-bloedite jel örneklerinin IR-spektrum analizi.

\begin{tabular}{|c|c|c|c|}
\hline Örnek & Dalga Sayısı $\left(\mathrm{cm}^{-1}\right)$ & Tür & Kaynak \\
\hline \multirow{7}{*}{$\mathrm{PVA}-\mathrm{Na}_{2} \mathrm{Ni}\left(\mathrm{SO}_{4}\right)_{2} \cdot 4 \mathrm{H}_{2} \mathrm{O}$} & 599 & asimetrik S-O & {$[1],[2]$} \\
\hline & 638 & asimetrik S-0 & [1], [2] \\
\hline & 812 & $\mathrm{C}-\mathrm{O}$ & [3] \\
\hline & 980 & $\mathrm{Ni}^{-B l o e d i t e ~} \mathrm{SO}_{4}{ }^{2-}$ & [1], [2] \\
\hline & 1039 & $\mathrm{C}-\mathrm{H}$ & [3] \\
\hline & 1091 & asimetrik ve simetrik $\mathrm{SO}_{4}^{2-}$ & {$[1],[2]$} \\
\hline & 1171 & asimetrik ve simetrik $\mathrm{SO}_{4}{ }^{--}$ & {$[1],[2]$} \\
\hline \multirow{7}{*}{$\mathrm{PVA}-\mathrm{Na}_{2} \mathrm{Mg}\left(\mathrm{SO}_{4}\right)_{2} \cdot 4 \mathrm{H}_{2} \mathrm{O}$} & 601 & asimetrik S-O & [1], [2] \\
\hline & 639 & asimetrik S-O & {$[1],[2]$} \\
\hline & 813 & $\mathrm{C}-\mathrm{O}$ & [3] \\
\hline & 987 & $\mathrm{Mg}$-Bloedite $\mathrm{SO}_{4}{ }^{2--}$ & {$[1],[2]$} \\
\hline & 1042 & $\mathrm{C}-\mathrm{H}$ & [3] \\
\hline & 1096 & asimetrik ve simetrik $\mathrm{SO}_{4}{ }^{2-}$ & {$[1],[2]$} \\
\hline & 1168 & asimetrik ve simetrik $\mathrm{SO}_{4}^{2-}$ & {$[1],[2]$} \\
\hline
\end{tabular}
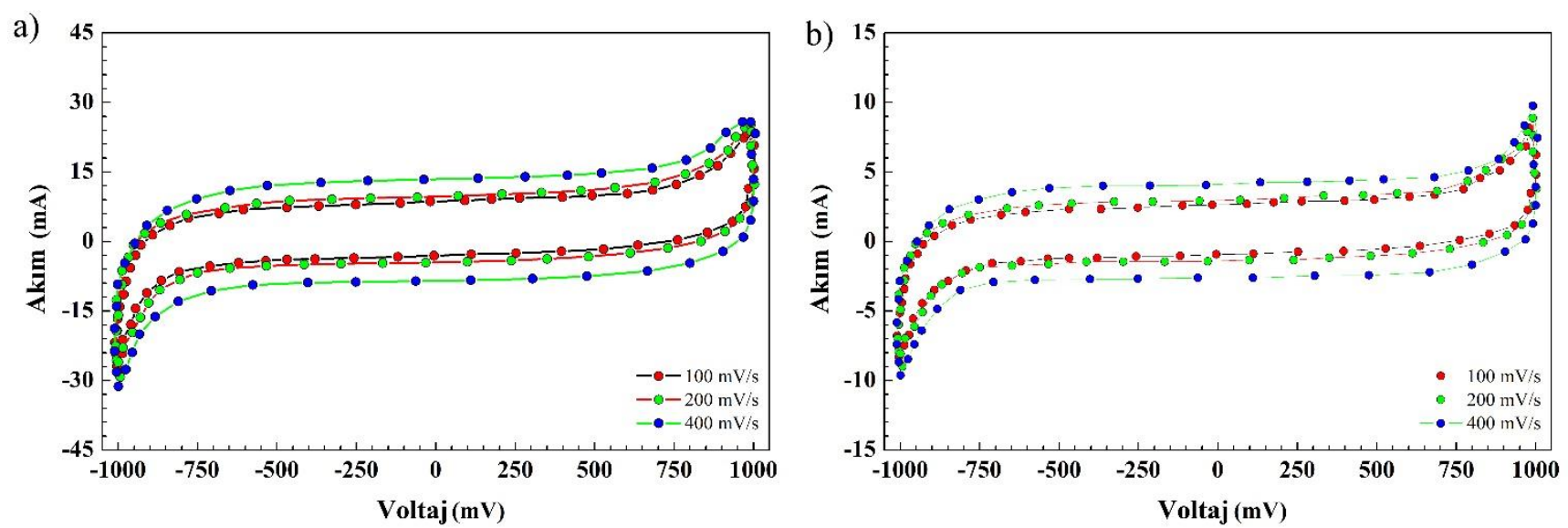

Şekil 2. Farklı tarama hızlarına bağlı olarak cv analizi. a) Ni-bloedite, b) Mg-bloedite. 
Şekil 2 Ni-bloedite ve Mg-bloedite cv ölçüm sonuçlarını göstermektedir. Bu aşamada cv ölçümleri her bir tarama hızı için 3' er döngü olarak yapılmış ve olası döngü sonrası değişim olup olmadığı analiz edilmiştir. 3' er döngü süresince herhangi bir anomali gözlemlenmezken Şekil 2' de daha net karşılaştırma yapılabilmesi için cv ölçümlerinin sadece 1 döngüsüne ait sonuçlar konulmuştur.

Şekil 2' nin genel analizine göre $\mathrm{Ni}$ ve Mg-bloedite jel elektrolitler $\pm 1 \mathrm{~V}$ aralı̆̆ında kalıcı kapasitif akım özelliği göstermektedir. Şekil 2 dikkatli incelendiği zaman Ni-bloedite örneklerinin Mgbleodite örneklerine göre daha yüksek miktarda akım sağladığı belirlenmiştir. Özellikle süperkapasitörlerde karakteristik cv ölçüm sonuçları "rectangular shape" olduğu göz önüne alındığında her iki örneğinde bu özelliğe yatkın olduğu belirlenmiştir (Demirel, 2020).

a)

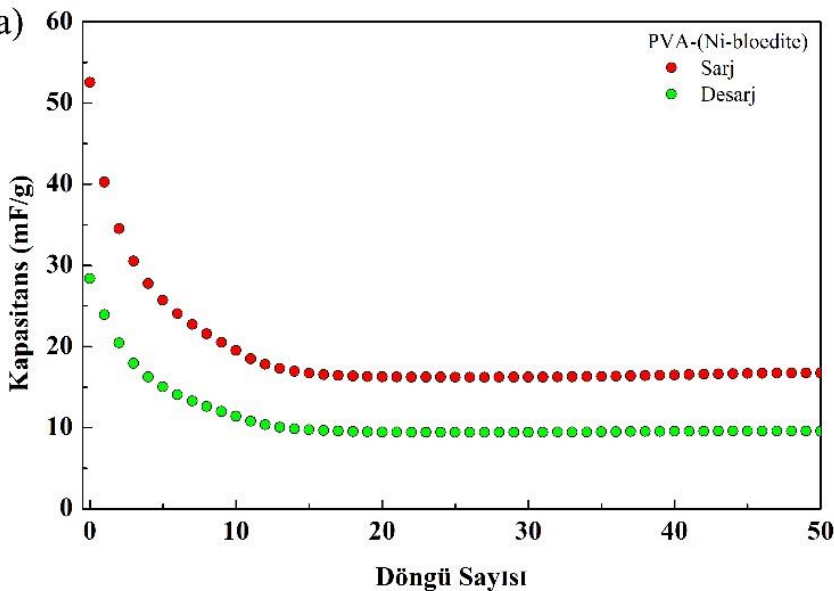

c)

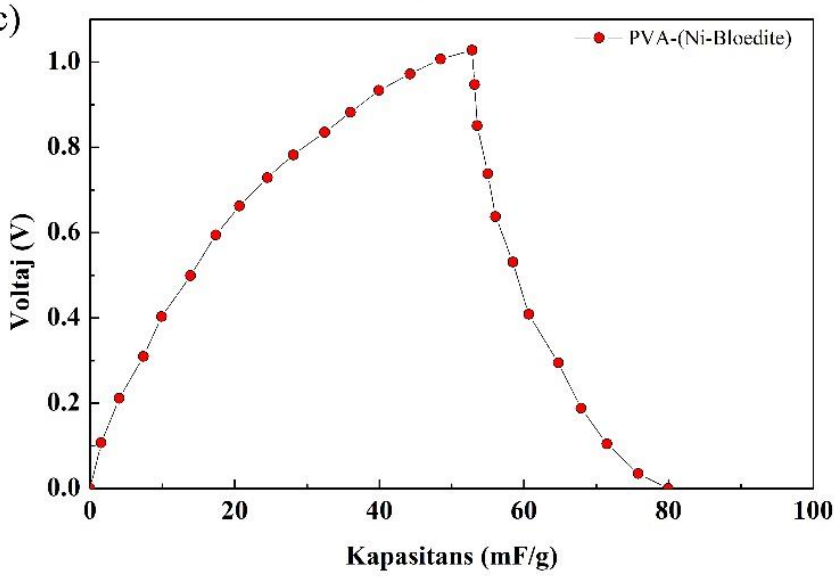

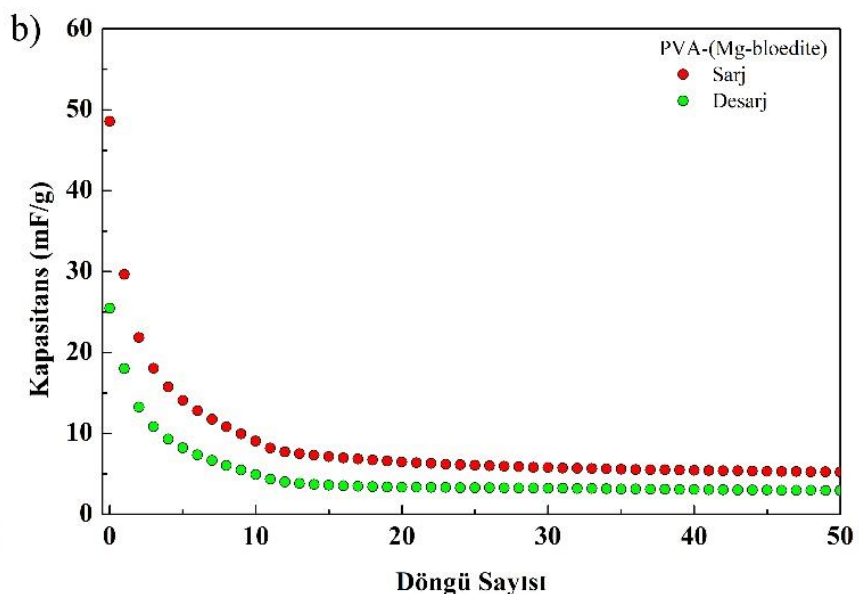

d)

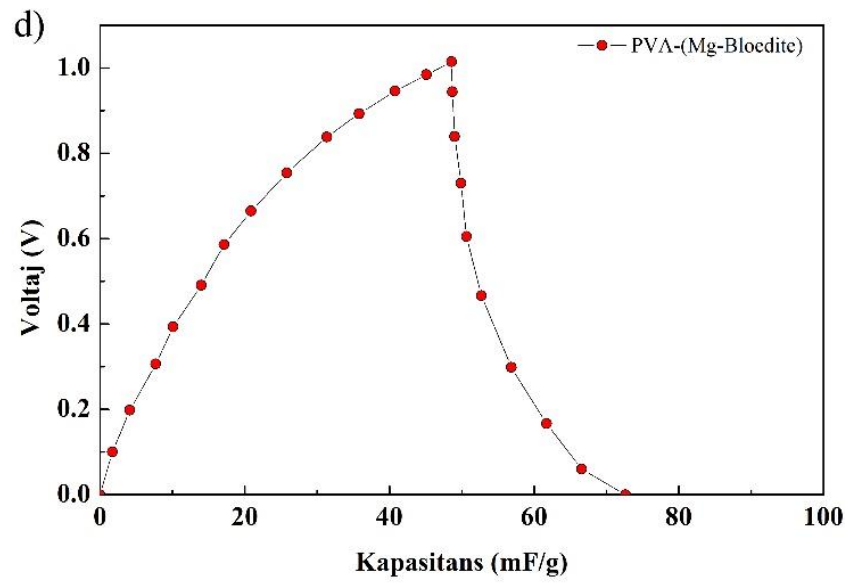

Şekil 3. $\mathrm{Ni}$ ve Mg-bloedite Jel elektrolitlerinin kapasitif performansları. a) Ni-bloedite şarj-deşarj performansı, b) Mgbloedite bloedite şarj-deşarj performansı, c) Ni-bloedite ilk döngü performansı, d) Mg-bloedite ilk döngü performansı.

Şekil 3 Ni-bloedite ve Mg-bloedite jel elektrolitlerinin kapasitif performanslarını göstermektedir. Elde edilen sonuçlar incelendiği zaman $\mathrm{Ni}$-bloedite ve $\mathrm{Mg}$-bloedite elektrolitlerinin kapasitans seviyeleri miliFarad düzeylerindedir. Ortalama 10 döngü sonrasında ise kararlı bir kapasite performansı sergilemektedirler. Şekil 3-a Ni-bloedite için 50 döngü performansını göstermektedir. 1. döngüde deşarj kapasitesi $28.4 \mathrm{mF} \mathrm{g}^{-1}$ iken 10. döngü sonrasında kapasite değeri $\sim 11 \mathrm{mF} \mathrm{g}^{-1}$ seviyesine düşmekte ve kalan 40 döngü süresince bu seviye çok değişmeden korunmaktadır. Şekil 3-b Mg-bloedite için 50 döngü performansını göstermektedir. Mg-bloedite jel elektroliti 1. döngüde deşarj kapasitesi $25.48 \mathrm{mF} \mathrm{g}^{-1} \mathrm{iken}$ 10. döngüden sonra bu değer $4.89 \mathrm{mF} \mathrm{g}^{-1}$ seviyesine düşmekte ve 50. Döngü sonunda bu değer $2.92 \mathrm{mF}$ $\mathrm{g}^{-1}$ değerine kadar düşmektedir. Çizelge 2 bazı spesifik şarj-deşarj döngülere ait kapasitans değerlerini göstermektedir. Çizelge 2' de bulunan veriler karşılaştırıldığ 1 zaman Ni-bloedite jel elektrolitinin 5 . döngüden itibaren Mg-bloedite jel elektrolitine göre 2 kattan daha fazla bir kapasitans performans1 
göstermektedir. Bunun en temel sebebi olarak viskozite gösterilebilir (McCormick vs ark., 1986). PVABloedite jel elektrolitlerde bir nevi tuz vazifesi gören Ni ve Mg-bloedite jel elektrolitleri viskoziteye direkt olarak etki etmektedir. Elektrolitlerde viskozite artışı elektriksel iletkenliği düşürmekte ve buna bağlı olarak iyon ve elektron hareketliliğini azaltarak kapasite düşüklügünne neden olmaktadır (McCormick vs ark., 1986). Diğer taraftan viskozitenin düşük olması elektriksel iletkenliği arttırmakta ve kapasitif performansın yükselmesi anlamına gelmektedir. Bu nedenle Mg-bloedite jel elektrolitinin daha düşük kapasitif performansa sahip olması daha yüksek viskozite ile ilişkilendirilebilir. Şekil 3-c ve d ilk döngüye bağlı şarj-deşarj grafiğini göstermektedir.

Çizelge 2. Döngü sayısına bağlı Ni-bloedite ve Mg-bloedite elektrolitlerine ait şarj-deşarj kapasite değerleri.

\begin{tabular}{|c|c|c|c|c|c|c|c|c|}
\hline \multirow{3}{*}{ Elektrolit } & \multicolumn{8}{|c|}{ Kapasitans $\left(\mathrm{mF} \mathrm{g}^{-1}\right)$} \\
\hline & \multicolumn{2}{|c|}{ 1. döngü } & \multicolumn{2}{|c|}{ 5. döngü } & \multicolumn{2}{|c|}{ 10. döngü } & \multicolumn{2}{|c|}{ 50. döngü } \\
\hline & Ch. & Dch. & Ch. & Dch. & Ch. & Dch. & Ch. & Dch. \\
\hline Ni-bloedite & 52.5 & 28.4 & 25.70 & 15.03 & 19.05 & 11.04 & 16.75 & 9.57 \\
\hline Mg-bloedite & 48.58 & 25.48 & 14.08 & 8.19 & 9.04 & 4.89 & 5.21 & 2.92 \\
\hline
\end{tabular}

Ch: Şarj kapasitansı ; Dch: Deşarj kapasitansı

Çizelge 3 su bazlı sıvı elektrolitler ile PVA bazlı jel elektrolitlere ait kapasitif performans karşılaştırmasını göstermektedir. Jel elektrolitlerin kapasitans değerleri beklendiği gibi su bazlı elektrolitlere göre daha düşük elde edilmiştir (Abouelamaiem ve ark., 2018; Latifatu ve ark.,2016; Abbas ve ark., 2014; Fic ve ark., 2012;). Bunun en önemli etkenlerinden biri su bazlı elektrolit aktif maddeleri $\left(\mathrm{HCl}, \mathrm{NaCl}, \mathrm{NaNO}_{3}\right.$ gibi) kapasitör içince daha kolay polarize olabilmesidir. Örnek olarak su bazlı $\mathrm{HCl}$ elektrolitinde $\mathrm{H}^{+}$ve $\mathrm{Cl}^{-}$iyonlaşmalarının ardından kutuplaşma gerçekleşirken, bu iyonların elektrotlara doğru hareketleri sıvı ortamda rahatlıkla gerçekleşmektedir. Jel elektrolitlerde ise bu durumu zorlaştıran bazı etkileşimler bulunmaktadır. Sıvı ortamda iyon-atom, iyon-molekül, iyon-iyon, iyon-safsızlık gibi etkileşimler daha minimal düzeyde gerçekleşirken jel elektrolitlerde bu etkileşimler daha fazla olmaktadır (Menzel ve ark., 2019; Ue ve ark., 1996). Ayrıca, jel formda sıv1 forma göre viskozitenin daha yüksek olması etkileşimleri arttırırken aynı zamanda kapasitif performansta düşüş sağlamaktadır.

Kapasitörlerin performansına etki edebilecek bir diğer faktör elektrolitin kolay iyonize olabilmesidir. Örnek olarak $\mathrm{NaCl}$ tuzu kolay bir şekilde iyonize olarak $\mathrm{Na}^{+}$ve $\mathrm{Cl}^{-}$iyonlarını oluşturabilmektedir. Bu durum Ni-bloedite $\left(\mathrm{Na}_{2} \mathrm{Ni}\left(\mathrm{SO}_{4}\right)_{2} \cdot 4 \mathrm{H}_{2} \mathrm{O}\right)$ ve Mg-bloedite $\left(\mathrm{Na}_{2} \mathrm{Mg}\left(\mathrm{SO}_{4}\right)_{2} \cdot 4 \mathrm{H}_{2} \mathrm{O}\right)$ yapılarında daha kompleks yapıdadır. Özellikle FTIR analizlerinde de görüldüğü gibi $\mathrm{SO}_{4}{ }^{2-}$ gruplarının yüksek seviyede titreşimleri $\mathrm{Na}^{+}$oluşumlarında olumsuz etki yapabilmektedir. 2015 yılında Moon ve arkadaşlarının yapmış olduğu süperkapasitör çalışmasında Agarose- $\mathrm{NaCl}$ jel elektrolitin performansı araştırılmıştır (Moon ve ark, 2015). Bu çalışma sonucunda Agarose- $\mathrm{NaCl}$ ile 286,9 $\mathrm{Fg}^{-1} \mathrm{kapasite}$ değerine ulaşılmıştır. Elde edilen bu değer hem geleneksel jel elektrolitlerden daha yüksek hem de sıvı elektrolitlerle yakın bir performanstadır. Moon ve arkadaşları bu durumu Agarose yapısındaki yüksek porlu yapı ile Agarose' in iyon transferini kolaylaştırması ve $\mathrm{NaCl}$ tuzunun kolay iyonizasyonundan kaynaklandığını belirtmiştir. Benzer şekilde bu durum, özellikle PVA-bloedite jel elektrolitlerin düşük kapasitans değerlerini de açıklamada yardımcı olmaktadır. Yani S-O gruplarında meydana gelen baskın titreşimler, Ni-S-O ve Mg-S-O bağ kafesleri içinde kalan $\mathrm{Na}$ atomlarının iyonlaşmasında zorluk çıkarabilmektedir. Bunun sonucu olarak da kapasitans değerlerinde istenilen yüksek verim sağlanamamaktadır.

Elektrot faktörü göz önüne alındığında ise PVA-bloedite jel elektrolitlerinin kapasitörlerde ilk kez denenmesi, bu elektrolitlerden alınabilecek maksimum değerin belirlenmesi büyük önem taşımaktadır. Bu nedenle kapasiteye en az katkısı olacak paslanmaz çelik folyo kullanılmıştır. Ayrıca, 
Çizelge 3' de kullanıldığı kapasitörlerde yüksek performans sağlayan aktif karbon ve daha yüksek kapasiteye sahip su bazlı elektrolitler ile bir karşılaştırma yapılmıştır. Her ne kadar PVA-bloedite jel elektrolitlerin kapasitans değerleri diğer jel elektrolitlere oranla daha az olsa bile elde edilen kapasitans değerlerinin farklı elektrot tipleri ile arttırılabileceği aşikardır. Çünkü şarj-deşarj süreçlerinde elektrolitlerde iyonlaşmalar meydana gelmekte ve elektrotlara yönelen iyonlar elektrotlar ile kimyasal bağ yapabilmektedir. Yapılan bu bağların fazlalığı ise kapasitans değerini arttırmaktadır. Bu kapsamda çelik folyo elektrotlar sahip oldukları yüksek yüzey gerilimi nedeni ile iyonik băg yapamadığı bilinmektedir. Bunun anlamı PVA-bloedite örneklerde kullanılabilecek farklı elektrot türleri ile daha yüksek kapasitans değerlerinin elde edilmesi mümkündür (Abouelamaiem ve ark., 2018; Latifatu ve ark.,2016; Abbas ve ark., 2014; Fic ve ark., 2012). Bu kapsamda bir sonraki deneysel çalışma farkl1 elektrot türleri üzerine gerçekleştirilecektir.

Çizelge 3. Değişik su bazlı elektrolitler ve PVA bazlı jel elektrolitlere ait spesifik kapasite değerleri.

\begin{tabular}{|c|c|c|c|c|c|}
\hline Elektrolit & Tür & Elektrot Tipi & $\Delta \mathrm{V}$ & Kapasite $\left(\mathrm{F} \mathrm{g}^{-1}\right)$ & Ref. \\
\hline $\mathrm{H}_{2} \mathrm{SO}_{4}$ & Su bazlı & Aktif Karbon & $0-1$ & 158 & [1] \\
\hline $\mathrm{HCl}$ & Su bazlı & Aktif Karbon & $0-1$ & 100 & {$[1]$} \\
\hline $\mathrm{NaNO}_{3}$ & Su bazli & Aktif Karbon & $0-0.6$ & 116 & [2] \\
\hline $\mathrm{KOH}$ & Su bazl1 & Aktif Karbon & $0-1$ & 140 & {$[3]$} \\
\hline $\mathrm{Li}_{2} \mathrm{SO}_{4}$ & Su bazlı & Aktif Karbon & $0-2.2$ & 180 & {$[4]$} \\
\hline $\mathrm{PVA}-\mathrm{H}_{2} \mathrm{SO}_{4}$ & Jel & Aktif Karbon & $0-1$ & 0.0385 & {$[5]$} \\
\hline PVA-Borax & Jel & Aktif Karbon & $0-1$ & 0.072 & {$[5]$} \\
\hline PVA-Na ${ }_{2} \mathrm{Ni}\left(\mathrm{SO}_{4}\right)$ & Jel & Çelik Folyo & $0-1$ & 0.028 & Bu çalışma \\
\hline PVA-Na $2 \mathrm{Mg}\left(\mathrm{SO}_{4}\right)$ & Jel & Çelik Folyo & $0-1$ & 0.025 & Bu çalışma \\
\hline
\end{tabular}

([1]: Latifatu ve ark.,2016; [2]: Fic ve ark., 2012 ; [3]: Abouelamaiem ve ark., 2018; [4]: Abbas ve ark., 2014; [5]: Demirel, 2020)

\section{SONUÇ}

Yapılan deneysel çalışmalar sonucunda PVA-Na $2 \mathrm{X}\left(\mathrm{SO}_{4}\right)_{2} \cdot\left(4 \mathrm{H}_{2} \mathrm{O}\right)(\mathrm{X}=\mathrm{Mg}, \mathrm{Ni})$ malzemeleri başarılı bir şekilde sentezlenmiştir. Yapısal karakterizasyon ölçümlerinde jel Ni ve Mg-bloedite yapıları benzer özelliklere sahip olduğu ve her iki yapıda $\mathrm{SO}_{4}{ }^{2-}$ titreşimlerinin baskın olduğu gözlemlenmiştir. Elektrokimyasal cv grafiklerinde genel olarak karakteristik süperkapasitör özelliği görülmüştür. Çelik folyo elektrotlar ile oluşturulan basit kapasitör uygulamalarında ise $\mathrm{Ni}$ ve $\mathrm{Mg}$-bloedite jel elektrolitleri miliFarad seviyesinde kapasite değerleri sağlamıştır. Şarj-deşarj döngüsel kapasite sonuçlarına göre Nibleodite elektroliti ile 50 döngü sonunda $9.57 \mathrm{mF} \mathrm{g}^{-1}$ deşarj kapasite değeri, Mg-bleodite elektroliti ile $2.92 \mathrm{mF} \mathrm{g}^{-1}$ deşarj kapasite değeri elde edilmiştir. Ni ve Mg-bloedite elektrolitleri arasında oluşan kapasitif performans farkı viskozite ile ilişkilendirilmiştir. Yani PVA-(Mg-bloedite) jel elektrolitlerinde viskozitenin daha yüksek olması nedeni ile kapasitenin daha düşük olduğu düşünülmektedir. Sonuç olarak Ni ve Mg-bloedite yapılarının kapasitörler için jel elektrolit özelliği gösterdiği ve Ni-bloedite yapısının Mg-bloedite yapısına göre daha yüksek performanslı olduğu belirlenmiştir.

\section{KAYNAKLAR}

Abbas Q, Pajak D, Frackowiak E and Beguin F, 2014. Effect of binder on the performance of carbon/carbon symmetric capacitors in salt aqueous electrolyte. Electrochim.Acta 140: 132-138.

Abouelamaiem D I, He G, Parkin I, Neville T P, Jorge A B, Ji S, Wang R, Titirici M M, Shearing P R and Brett D J L, 2018. Synergistic relationship between the threedimensional nanostructure and electrochemical performance in biocarbon supercapacitor electrode materials. Sustainable Energy and Fuels DOI: 10.1039/c7se00519a

Chang Y-W, Wang1y E, Shin G, Han J-E and Mather P T, 2007. Poly(vinyl alcohol) (PVA)/sulfonated polyhedral oligosilsesquioxane (sPOSS) hybrid membranes for direct methanol fuel cell applications. Polymers for Advanced Technologies 18: 535-543. 
Demirel S, 2020. Temperature Dependent Polarization Effect and Capacitive Performance Enhancement of PVA-Borax Gel Electrolyte. International Journal of Electrochemical Science 15: 2439-2448.

Fic K, Lota G, Meller M and Frackowiak E, 2012. Novel insight into neutral medium as electrolyte for high-voltage supercapacitors. Energy Environental Science 5: 5842-5850.

González A, Goikolea E, Barrena J A, Mysyk R, 2016. Review on Supercapacitors: Technologies and materials. Renewable and Sustainable Energy Reviews 58: 189-1206.

Kasatkın A V, Nestola F, Plasıl J, Marty J, Belakovskıy D I, Agakhanov A A, Mills S J, Pedron D, Lanza A, Favaro M, Bianchın S, Lykova I S, Golias V, nad Bırch W D, 2013. Manganoblodite, $\mathrm{Na}_{2} \mathrm{Mn}\left(\mathrm{SO}_{4}\right) 2 \cdot 4 \mathrm{H}_{2} \mathrm{O}$, and cobaltoblodite, $\mathrm{Na}_{2} \mathrm{Co}\left(\mathrm{SO}_{4}\right)_{2} \cdot 4 \mathrm{H} 2 \mathrm{O}$ : two new members of the blodite group from the Blue Lizard mine, San Juan County, Utah, USA, Mineralogical Magazine 77: 367-383.

Latifatu M, Lee H S, Yoon C S, Oh J, Park J H, Park J W, Ko J M, 2016. Supercapacitive Properties of Activated CarbonQuinone Derivative Composite Electrode in Different Hydrogen ion Conducting Electrolytes. International Journal of Electrochemical Science 11: 5353-5363.

Marinova D M, Zhecheva E N, Kukeva R R, Markov P V, Nihtianova D D, Stoyanova R K, 2017. Mixed sodium nickelmanganese sulfates: Crystal structure relationships between hydrates and anhydrous salts. Journal of Solid State Chemistry 250: 49-59.

McCormick CL, Blackmon KP, Elliott DL, 1986. Water-soluble copolymers. XIII. Copolymers of acrylamide with sodium3-acrylamido-3-methylbutanoate: Solution properties. Journal of Polymer Science Part A: Polymer Chemistry 24: 2619-2634.

Menzel J, Frackowiak E, Fic K, 2019. Electrochemical capacitor with water-based electrolyte operating at wide temperature range. Journal of Power Sources 414: 183-191.

Moon WG, Kim G-P, Lee M, Song HD, and Yi J, 2015. A Biodegradable Gel Electrolyte for Use in High-Performance Flexible Supercapacitors. ACS Applied Materials Interfaces 7: 3503-3511.

Pal B, Yang S, Ramesh S, Thangadurai V, and Jose R, 2019. Electrolyte selection for supercapacitive devices: A critical review. DOI: 10.1039/C9NA00374F

Reynaud M, Rousse G, Abakumov A M, Sougrati M T, Tendeloo G V, Chotard J-N and Tarascon J-M, 2014. Design of new electrode materials for Li-ion and $\mathrm{Na}$-ion batteries from the bloedite mineral $\mathrm{Na}_{2} \mathrm{Mg}\left(\mathrm{SO}_{4}\right)_{2} \cdot 4 \mathrm{H}_{2} \mathrm{O}$. Journal of Materials Chemistry A 2: 2671.

Rong-rong Z, Yi-zong H, Yu-hong F, 2011. Crystal growth, optical spectra and thermal properties $\mathrm{Of} \mathrm{Na}_{2} \mathrm{Ni}_{(}\left(\mathrm{SO}_{4}\right)_{2} \cdot 4 \mathrm{H}_{2} \mathrm{O}$ Crystal. Advanced Materials Research 216: 312-315.

Ue M, Takeda M, Suzuki Y, Mori S, 1996. Chemical stability of $\gamma$-butyrolactone-based electrolytes for aluminum electrolytic capacitors. Journal of Power Sources 60: 185-190.

Ventosa E, Paulitsch B, Marzak P, Yun J, Schiegg F, Quast T, and Bandarenka A S, 2016. The Mechanism of the Interfacial Charge and Mass Transfer during Intercalation of Alkali Metal Cations. Advanced Science DOI: 10.1002/advs.201600211

Yahia HB, 2019. Crystal structure of a new polymorphic modification of $\mathrm{Na}_{2} \mathrm{Mn}_{3}\left(\mathrm{SO}_{4}\right)_{4}$. Crystalline Materials 234: 11-12.

Zhong C, Deng Y, Hu W, Qiao J, Zhang L and Zhang J, 2015. A review of electrolyte materials and compositions for electrochemical supercapacitors. Chemical Society Reviews 44: 7484-7539. 